\title{
Para uma Metodologia Visual eM AÇÃo NA INVESTIGAÇÃO-CRIAÇÃO: O EXEMPLO DE SORODAS
}

\author{
Carole Brandon \\ Laboratório de Línguas, Literaturas, Sociedades, Estudos Transfronteiriços e In- \\ ternacionais, Universidade Savoie Mont Blanc, França \\ Marc Veyrat \\ Laboratório de Línguas, Literaturas, Sociedades, Estudos Transfronteiriços e In- \\ ternacionais, Universidade Savoie Mont Blanc, França
}

\begin{abstract}
RESUMO
Este texto apresenta uma metodologia em funcionamento no Departamento de Comunicação Hipermédia da Universidade Savoie Mont Blanc, França, que se baseia, há vários anos, numa estreita colaboração entre as Ciências da Informação/Comunicação e as Ciências da Arte, a fim de permitir a produção de dispositivos inovadores na investigação-criação de artes digitais, nomeadamente dispositivos construídos em hipermédia. Um testemunho desta estratégia é a obra SORODAS de Carole Brandon, planeada para o Atelier-Laboratoire IDÉFI-CréaTIC[S] Langue[S] \& Patrimoine[S], que seria deslocalizado para as ilhas de Mayotte no Oceano Índico, em 2018. Mesmo que a viagem da equipa deste projeto tenha sido finalmente cancelada dois dias antes da partida, devido a eventos e manifestações ocorridos na ilha, este dispositivo hipermédia e artístico foi acompanhado por um longo trabalho preliminar interdisciplinar, de pesquisa em antropologia visual e metodologia de projeto, conduzida em conjunto pela equipa de Ghislaine Chabert e Carole Brandon. Contando com a colaboração dos alunos do Mestrado Digital Creation, este território de Mayotte, difícil de circunscrever devido ao seu afastamento geográfico e ao seu passado tumultuoso, não poderia decentemente ser abordado sem diversas precauções entretanto tomadas. O presente texto inclui uma amostra dos resultados obtidos, apresentados parcialmente num estilo de escrita inspirado na linguagem das redes sociais e experimentado no projeto. Por exemplo, os autores escrevem “®ver" em vez de "rever", para sublinhar a dualidade do processo de "(re)visão" no tempo. Ou por vezes substituem os parêntesis simples ( ) por (-! !-), ou seja, usam a notação emojis, formada por ideogramas e smylies, muito frequente no ciberespaço e nas redes sociais digitais.
\end{abstract}

Palavras-chave

SORODAS; investigação-criação; arte digital; hipermédia; Mayotte

\section{TOWARDS A VISUAL METHODOLOGY IN RESEARCH- CREATION: THE EXAMPLE OF SORODAS}

\begin{abstract}
This text presents a methodology in operation at the Department of Hypermedia Communication at Savoie Mont Blanc University, France, which for many years has been based on close collaboration between the Information/Communication Sciences and Art Sciences, in order to enable the production of innovative devices in research-creation of digital arts, namely devices built in hypermedia. A testimony of this strategy is Carole Brandon's work named SORODAS, planned for the IDÉFI-CréaTIC Atelier-Laboratoire [S] Langue [S] \& Patrimoine [S], which would
\end{abstract}


be relocated to the Mayotte Islands in the Indian Ocean in 2018. Even if the trip by the project team was finally canceled two days before departure, due to events and demonstrations occurred in the island. This hypermedia and artistic device was accompanied by a long interdisciplinary preliminary work, research in visual anthropology and project methodology conducted jointly by Ghislaine Chabert and Carole Brandon team. With the collaboration of Digital Creation Master students, this territory of Mayotte, difficult to circumscribe due to its geographical remoteness and tumultuous past, could not be decently approached without several precautions taken in the meantime. The present text includes a sample of the results obtained, presented partially in a writing style inspired by the language of social networks and experienced in the project. For example, the authors write "®view" instead of "review" to underline the duality of the "(re)vision" process in time. Or sometimes they replace simple parentheses () with (-! !-), that is, they use an emoji notation, formed by ideograms and smylies, very common in cyberspace and digital social networks.

\section{KEYWORDS}

SORODAS; research-creation; digital art; hypermedia; Mayotte

Figura 1: Este i+D/sign (-! information + Design / Sign !-) é um signo marcador da obra de arte hipermédia SORODAS. Preparado para uma possível tatuagem na pele de mulheres piratas

Créditos: Marc Veyrat, Société i Matériel, T i-LÉGAL—O4O-SORODAS-04, Tatoo i-T+O-O, 2018

\section{INTRODUÇÃo \& PIRATE/AGE}

A metodologia em funcionamento no Departamento de Comunicação Hipermédia' da Universidade Savoie Mont-Blanc, baseia-se há já vários anos numa estreita colaboração entre as Ciências da Comunicação, da Informação e as Ciências da Arte, a fim

\footnotetext{
' Página do Departamento de Comunicação Hipermédia no Facebook disponível em https://www.facebook.com/ CommunicationHypermedia/
} 
de possibilitar a produção de dispositivos inovadores ${ }^{2}$ na investigação criativa ${ }^{3}$. A obra de arte Sorodas ${ }^{4}$ de Carole Brandon, planeada para o laboratório-oficina IDÉFI-CréaTIC Arte[S] Linguagem[S] \& Património[S]', e que seria realocada em 2018 para Mayotte, é um exemplo perfeito disso mesmo. De fato, este dispositivo hipermédia e artístico foi acompanhado por um longo trabalho preliminar e interdisciplinar de pesquisa em Antropologia Visual e metodologia de projetos, realizada em conjunto por Ghislaine Chabert e Carole Brandon. De facto, tendo em vista os alunos do Mestrado em Criação Digital, este território de Mayotte, de difícil acesso devido ao seu afastamento geográfico e ao seu passado tumultuado, não pôde ser abordado decentemente sem precaução.

Antes de mais, é necessário esclarecer que a designação Mayotte se refere a um conjunto de duas ilhas, Grande-Terre e Petite-Terre, que originalmente fazem parte geográfica e histórica - do arquipélago de Comores, localizado perto de Madagáscar no canal de Moçambique. Mas, diferentemente do resto do arquipélago que vota $96 \%$ pela independência, elas preferem, após dois referendos sucessivos (-! em 1975 e 1976 !-), permanecerem francesas. Essas ilhas, separadas agora do resto do arquipélago, que se tornou um estado independente - encerrando assim um parêntese aberto em 1841 - irão (R-CRIAR-SE incessantemente com os seus vizinhos desaparecidos, um Amo-te próximo e um Eu também não distante, um aqui e ali particularmente desconfortável. De fato, se Mayotte se tornou em 2011 um departamento e uma região ultramarinos franceses, e depois em 2014 uma região ultraperiférica da União Europeia, as tensões com as Comores permanecem constantes, numerosas e aparentemente irreversíveis, especialmente em torno de questões de imigração. E foram as manifestações violentas, sempre atuais, que causaram o cancelamento in extremis de nossa viagem/oficina IDÉFI-CréaTIC.

Uma tal escolha de permanecer no seio nacional, aprovada, ou mesmo incentivada pela França, que deseja manter nessa região interesses estratégicos - políticos, económicos e militares - realiza-se sob a i+M/PULSÃO das chatouilleuses ${ }^{6}$ (-! isto é, as mulheres "coceguentas" ou "suscetíveis", que inspiraram a autora para a obra SORODAS! -). Ao organizarem, estrategicamente juntas, essa recusa de independência em torno do mencionado referendo em 1976, essas mulheres tomam o poder e tornam-se, voluntária ou involuntariamente, porta-vozes de uma consciência feminista que prossegue e finalmente destaca o que já aconteceu desde 1971, na França, com o Manifesto

\footnotetext{
${ }^{2} \mathrm{O}$ trabalho interdisciplinar produzido entre Ciências da Comunicação da Informação e Ciências da Arte remonta à obtenção da tese CIFRE de Franck Soudan, que está disponível em https://www.academia.edu/20211446/Penombra, sob a direção de Jacques Ibanez- Bueno e Marc Veyrat, e o trabalho preliminar realizado por toda a equipa do Departamento de Comunicação Hipermédia em Bourg-en-Bresse, para Les chemins de la culture, disponível em https://youtu.be/_dXıiymbı6A

3 @-VER a este propósito LLSETI I G-SICA Art Communication Image Research Group I 2015no YouTube, disponível em https://youtu.be/AbJymp-psrQ

${ }^{4}$ A obra SORODAS continua a obra SIRESSES, disponível em https://www.carolebrandon.com/siresses

${ }_{5}^{5}$ Disponível em http://idefi-creatic.net/fr/publications/catalogues/

${ }^{6}$ Brandon escreve no documento entregue aos alunos para preparar o workshop: "este é um marco na história da manutenção de Mayotte como departamento e região francesa. Centenas de mulheres usavam cócegas (não listadas como crime) contra políticos pró-independência" (Brandon, documento preparatório do workshop do Departamento de Comunicação Hipermédia, 2018).
} 
das 343 vadias. Porque "este texto do manifesto", publicado a 1 de abril de 1971 na revista Politique Hebdo", sob o título "As abortadas tomam a palavra" (Parvard, 2010), e, em seguida, sob o título "Fui abortada", e finalmente com os nomes e assinaturas na revista Nouvel Observateur $n^{\circ} 334$ de 5 Abril de $1971^{9}$, inaugura o que poderia ser chamado de descolonização do corpo feminino.

Um ponto i+M/PORTANTE a ser destacado refere-se à inscrição deste workshop "Arte[S] Língua[S] e Património[S]" - que se segue aos precedentes ateliers-laboratórios deslocalizados em Malta - nos Ateliers-Laboratoires CréaTIC-IDÉFI.

No final de 2011, a Universidade de Paris 8 apresentou um projeto em resposta ao convite para o programa "Initiatives d'Excellence en Formations Innovantes", com parceiros como a Universidade Paris Nanterre, a Maison des Sciences Humaines Paris Nord, o Conservatoire National Supérieur d'Art Dramatique, os Archives Nationales e 37 parceiros estrangeiros. No início de 2012, o projeto CréaTIC é aceite e tem um orçamento de 5,2 miIhões de euros para oito anos. O projeto baseia-se em cinco princípios fundamentais: a criação como um mecanismo epistemológico de pedagogias inovadoras (-! no âmbito de ateliers-laboratórios! -), o uso sistemático de tecnologias digitais avançadas para o ensino e trabalho colaborativos, o apoio personalizado aos estudantes (-! do recrutamento ao diploma !-) no quadro de pedagogias fundadas em projetos, da avaliação e transparência dos resultados, e da integração profissional. O projeto começou no início do ano letivo de 2013-2014 com 15 cursos de mestrado e os 5 parceiros iniciais. A sua ambição contratual consistiu em expandir-se o mais rápido possível para um grande número de estudantes (-! meta de 5.000 alunos para o final do programa em 2019!) - dentro da estrutura de cursos de

\footnotetext{
${ }_{7}$ Numa França já em ebulição das questões da contracepção (lei Neuwirth, 1967) e do aborto, este manifesto nasceu sob o ímpeto de uma ideia de Jean Moreau e Nicole Muchnik. Este texto é uma iniciativa de Anne Zelensky e Christine Delphy, assistidas na redação por Simone de Beauvoir. O Manifesto será seguido pelo processo de Bobigny em 1972. Isso levará a um projeto de lei defendido por Simone Veil, Ministra da Saúde em 1974, para a descriminalização do aborto, mas sem reconhecê-lo como um direito: Lei Veil votada em 17 de janeiro de 1975. Disponível em https://www.legifrance.gouv.fr/ affichTexteArticle.do;jsessionid=2C48426D1ADo031BAE312B1617DE9E2F.tpdila16v_1?idArticle=LEGIARTI000006695557\& cidTexte $=$ LEGITEXTooooo6068506\&dateTexte $=20151230$

${ }^{8}$ Jornal de esquerda fundado em 1970 por Paul Noirot até 1981.

9 É graças a um conto, A Princesa e o seu Mac, escrito na rede social Facebook durante três anos, que percorreremos aquilo que esses personagens representam na zona instável e móvel dos seus encontros. A Princesa e o seu Mac designam um personagem fictício, um corpo real e máquinas. A princesa introduz ponto de vista feminino, interpretando um devir. $O$ Mac refere-se tanto à marca Apple que vende computadores Macintosh quanto a uma abreviatura na gíria francesa. Tentaremos formular a hipótese de que a arte parece materializar espaços particulares, entre corpos e máquinas. Este título Entre [corpo/máquina] caracteriza tais espaços que chamamos de flutuantes, com referência a moucharabieh e ao Ma Japonês. A compreensão dessa organização espacial e a conceção oriental de espaços-tempo parecem constituir um meio de considerar este 'entre corpo/máquina' como um espaço de resistência. Acima de tudo, promoveria a compreensão de nosso lugar no mundo para agir sobre o mundo. A partir de uma prática artística pessoal, examinaremos as necessidades de espaços flutuantes e em e extensão. Somente as nossas presenças entre o corpo e a máquina tornam visíveis os vínculos relacionais 'entre' as informações e as rotas operadas, 'entre' os nossos corpos e as nossas identidades. Uma tal pesquisa busca mostrar que a força das redes sociais na prática artística da autora, acompanha e gera as variabilidades do corpo e das nossas perceções em tempo real. O 'entre [corpo / máquina]' possibilita, de acordo com os ritmos que produz, tempos de impregnação e encontros em que agora extraímos forças vitais (Brandon, 2016).
} 
formação certificados e pela integração de outros cursos de Mestrados que buscam a certificação, como o Mestrado Criação Digital, do Departamento de Comunicação Hipermédia da Universidade de Savoie Mont-Blanc, que ingressou neste programa em final de 2015. Hoje, o CréaTIC possui 17 cursos de formação e 24 ateliers-laboratórios abertos a mais de 5000 estudantes. ${ }^{10}$

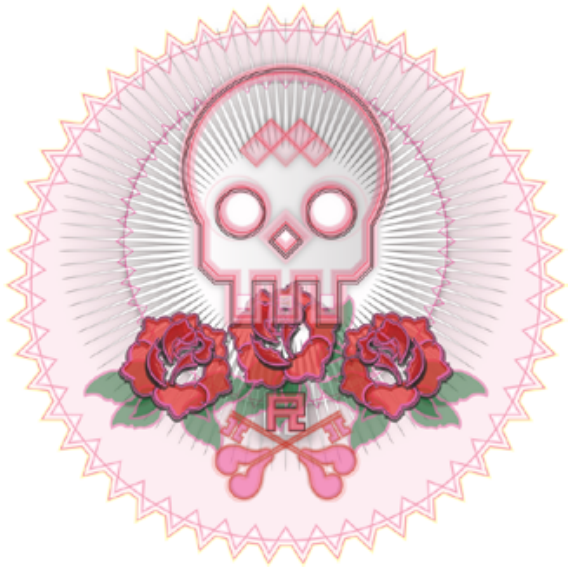

Figura 2: Este i+D/sign (-! information + Design / Sign !-) é um signo marcador de SORODAS

Créditos: Marc Veyrat, Société i Matériel, M-A+R-Y R-E+A-D_04, i+D/signe, 2018

\section{A OBRA SORODAS: MOBILIS I-N MOBILE ${ }^{11}$}

A obra SORODAS (-! que significa soldado na língua mahorais !-) inscreve-se no projeto SIRESSES sobre mulheres piratas. SIRESSES nasceu desse fascínio por essas mulheres que expressavam o seu desejo de autonomia e liberdade (-! o óbvio contraponto de La Princesse Q son $M A C^{2}$, escolhido como subtítulo da tese de Carole Brandon! -) incluindo a dificuldade de mapear as suas vidas e viagens como uma vontade inerente e, em última análise, muito contemporânea, de ir além do protocolo estatal das fronteiras. Além disso,

\footnotetext{
10 "O acompanhamento profissional e o enquadramento pedagógico também são implementados para melhor atender aos desafios da integração profissional dos alunos. Mais de 90 profissionais e professores em cada ano trocam, supervisionam e acompanham os alunos na realização do seu projeto. Enfim, é dada especial atenção à promoção de projetos dos estudantes e dos ateliers-laboratórios. Tanto na internet em rubricas específicas quanto no canal do YouTube e, de maneira mais geral, no Centre de Veille et d'Innovation [Centro de Monitoramento e Inovação] no momento da restituição das produções e encontros com parceiros estrangeiros". Retirado de http://idefi-creatic.net/fr/creatic/
}

"Se a escrita exata em latim é Mobilis in Mobili (-! móvel no elemento móvel! -), manteremos aqui a transcrição inicial, Mobilis in Mobile, encontrada em Vinte mil léguas submarinas na primeira edição datada de 1871 por Jules Vernes, (-! o erro foi corrigido na edição de 1880, bem como no romance $A$ ilha misteriosa, escrito em 1875 !-) e que também se refere ao quarto álbum de L'affaire Louis' trio, saído em 1993. Esta inscrição no Le Nautilus $®$-ENVIA diretamente ao i+D (sistema de Investigação e Desenvolvimento), permanecendo inevitavelmente em movimento nas/ entre/sobre os FLUXOS e ®-FLUXOS da rede - traduzida através da obra SIRESSES - para interrogar ou mesmo contrariar qualquer processo de controle ou de vigilância, descritos, por exemplo, por Michel Foucault em Surveiller et Punir (1993) (-! Ver abaixo! -)

${ }^{12}$ Disponível em http://idefi-creatic.net/fr/publications/catalogues/ 
o princípio das suas existência e sobrevivência depende inteiramente da sua invisibilidade através do disfarce e, em seguida, da visibilidade frequentemente acompanhada de histórias. Esta parte ficcional preenche as lacunas e as escolhas de partida dessas mulheres que têm em mãos um destino particular. Elas devem as suas visibilidades a fragmentos de documentos que surgem à superfície com o tempo. Uma imensa colagem de peças espalhadas para reconstituir um personagem localizado entre uma figura de heroína romântica e uma mulher real emancipando-se. ${ }^{13}$

Portanto, SORODAS interessa-se mais especificamente pela maneira como a palavra viaja, se mapeia e se transforma em i-MIGRANTE, criando consequentemente elos flutuantes, imergindo-nos em TRAJETOS de "i" entre os corpos femininos e as máquinas políticas de autoridade.

Igualmente, quando Camille Teyssier e Florian Plamont ${ }^{14}$ lançaram em 2017 a primeira versão do jogo urbano Brickx ${ }^{15}$ como resultado e graças ao atelier-laboratório IDÉFI-CréaTIC "Hypermedia \& Artistic Creation" deslocalizado para Malta, ao testar este jogo,

eu sou imediatamente interpelado por esta viagem, colado ao mapa e a esta navegação da errância. No ecrã do telemóvel portátil, desde a casa até uma certa escala de visão (-! não há possibilidade de zoom ou de "dezoom" i+M/PORTANTES! -), o aplicativo propõe uma apreensão do mapa por pedaços, necessariamente imprecisos, aproximativos e incapazes de contextualizar os seus movimentos e a sua situação. Um eco ressoa muito fortemente nessa experiência com as vidas e as histórias de mulheres piratas ${ }^{16}$.

Além disso, a aplicação Brickx submete-nos mais particularmente a uma vadiagem pictórica, por causa dos bugs ainda presentes no écran devido a diferenças nas camadas do mapa. No arrastar dos dedos,

conheço uma nova maneira de ver e experimentar o mapa do mundo. Essa escala i+M/POSTA, $®$-REDOBRADA pelos desenhos, pelas cores, propõe-nos apreender um mundo $®-A P R E S E N T A D O$ apenas regulado por uma busca sensível de zonas de cores, de atrito das camadas, de padrões, de ícones e desenhos estranhos. Cores, linhas e ícones incongruentes atravessam edifícios, superfícies de água e seções inteiras de desertos

\footnotetext{
${ }^{13}$ Extrato do documento escrito por Carole Brandon para apresentar o atelier-laboratório CréaTIC-IDÉFI Art[S] Langue[S] \& Patrimoine[S]. (Brandon, documento preparatório do workshop do Departamento de Comunicação Hipermédia, 2018)

${ }^{14}$ Camille Teyssier e Florian Plamont, na sequência dos seus Mestrados 2 HEl Hipermédia e Espaços Inteligentes, no Departamento de Comunicação Hipermédia / Universidade Savoie Mont Blanc, desenvolvem este projeto iniciado tanto no âmbito de um atelier-laboratório CréaTIC-IDÉFI de Paris 8 deslocalizado para Malta, criado e coordenado por Marc Veyrat, e simultaneamente no quadro da sua tese de mestrado. Hoje, acompanhados por diferentes estruturas, eles receberam, no Centro de Veille et d'Innovation, em 2017, na Torre Montparnasse, o Grande Prémio do Júri do concurso "Jeune Création d'Entreprise", criado pela CréaTIC-IDÉFI em parceria com Paris \& Co.

${ }^{5}$ Página do Facebook disponível em https://www.facebook.com/brickxProject/; site do projeto disponível em http://www. brickx.fr/

${ }^{16}$ Left-wing newspaper founded in 1970 by Paul Noirot until 1981.
} 
com falhas, contando tantas histórias individuais quanto coletivas. Usando o aplicativo Brickx (-! com a amável autorização dos criadores !-), existe (B-CRIAÇÃO de um passeio poético entre a minha experiência à distância, mas real, com tecnologia e essas fascinantes e lendárias histórias de mulheres piratas. Como parte do workshop-laboratório IDEFI-CréaTIC de Mayotte (-! criado e coordenado por Marc Veyrat! -) com alunos do Mestrado 1 Criação Digital de Chambéry e Paris e Mestrado 2 2ID, propus questionar a continuação deste projeto na fabricação de histórias através de cartografias sensiveis ${ }^{17}$, conectando desta vez o mapa resultante dessa rede de viagens em fragmentos (-? i+M/POSSÍVEIS fuites à la nage ?-) interpretados através de Brickx, no interior do território físico de Mayotte. Igualmente, de novo a partir do aplicativo, gravaram-se capturas de ecrã da minha viagem a Mayotte por meio de um telemóvel. Cada captura de tela é listada por 100 peças nos painéis do Pinterest. Cada painel do Pinterest é dedicado a uma mulher conhecida do Comando des Chatouilleuses de 1966 a 1975. (Brandon, documento preparatório do workshop do Departamento de Comunicação Hipermédia, 2018, p.1 $)^{18}$

Também é necessário sublinhar aqui a questão - central no departamento de Comunicação Hipermédia na Universidade de Savoie) - da criação de um dispositivo de pesquisa-criação associada à arte. Os autores inscreveram-no na linhagem das análises de Michel Foucault. O autor empregou o termo "dispositivo" na obra Surveiller et punir de 1975, na medida em que esse termo é utilizado para enfatizar que

a arte de governar situações de urgência e comportamentos indesejáveis depende de agenciamentos relacionais, de encontros de objetos sociotécnicos, humanos e não humanos, discursivos e materiais, que se articulam a arquiteturas adaptadas para maximizar os efeitos técnicos disciplinares que aí ocorrem. (Foucault, 2001, p. 229)

Mais tarde, na sua Histoire de la sexualité, em três volumes (Foucault, 1976, 1984a, 1984b), Foucault especifica na La Volonté de Savoir (1976) o conceito de dispositivo da sexualidade: como um conjunto de discursos, práticas médicas e arranjos arquitetónicos para restringir o onanismo e a sexualidade; ou este autor demonstra a emergência de dispositivos de sexualidade (-! Arqueologia dos discursos desde o século XVII !-) substituindo os dispositivos da aliança (-! um EU sujeito existente pelas suas genealogia e alianças! -).

Em termos concretos, inscrevemos voluntariamente qualquer dispositivo de investigação-criação sobre o limite poroso e instável de um ENTRE [CORPO/ MÁQUINA]

\footnotetext{
${ }^{17}$ @-VOIR a convocatória de trabalhos para o colóquio e a exposição "A Arte e as Cartografias Sensíveis", prevista para maio de 2020 em Chambéry, disponível em https://www.facebook.com/events/2434907713295790/

${ }^{18} \mathrm{O}$ trabalho interdisciplinar entre Informação, Comunicação e Ciências das Artes remonta à tese de Franck Soudan (2010), sob orientação de Jacques Ibanez-Bueno e Marc Veyrat, e ao trabalho preliminar levado a cabo por uma equipa do Departamento de Comunicação Hipermédia em Bourg-en-Bresse, para o Les Chemins de la Culture, disponível em https://youtu. be/_dXiiymbi6A.
} 
®-ATIVADO por sistemas biológicos, sociais e económicos. De certa forma, se, em primeiro lugar, estes dispositivos permitirem o surgimento de processos artísticos complexos - magnetizados por e ao redor de um EU sujeito reflexivo - $§$ TOMANDO / aprendendo a palavra - eles também nos informam sobre as relações de UM corpo. Com ao Outro. Estas relações, mantidas, modeladas com/por um EU EM JOGO externo, constrangedor, moral, social e político, sobrepondo-se assim à fragilidade, à emoção e ao MIM-EU de uma corporalidade interior fluida e suave. Concretamente, esta osmose melancólica, o calor radiante destas relações de trocas direcionadas ao Outro, incessantemente em ®CONSTRUÇÃO, são abaladas por esse invasor, um eSPAÇO externo agressivo e frio. Consequentemente, podemos apenas imaginar qualquer dispositivo na investigação-criação através de uma prática artística experimental e inovadora; este dispositivo permanece sem um modelo prévio porque localiza-se através da experiência fenomenológica de um território instável: uma zona de fronteira de interface, constan-

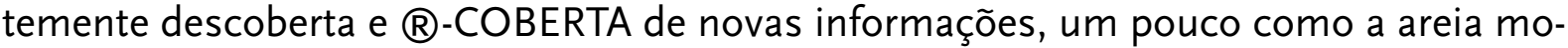
vediça, mais ou menos $\mathbb{R}$ COMPOSTAS formalmente, definitivamente por/neste lugar SEX-i do OUTRO ESTRANHO- $($ ) (-! Este grande Outro da psicanálise definido por Jacques Lacan !-).

Assim, este dispositivo escapa necessariamente, nessa/através da mobilidade elástica gerada a cada movimento, no EU devendo estar $($-COLOCADO sob o jugo do controlo. Além disso, abrindo uma operação de resistência entre EU e MIM; esse dispositivo provoca naturalmente - e isso, mesmo que as ferramentas sejam conhecidas uma forma de fuga, de evaporação sistémica ${ }^{19}$, desordem singular (-! entre EU e MIM! -)

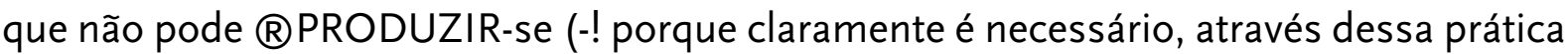
operativa, PRODUZIR e ®PRODUZIR constantemente a partir daquilo que já foi PRODUZIDO !-) sem hesitação, sem divagação, sem conflito.

\section{MILLE SABORDS (BRANDON, 2002)}

Qualquer ®SEMELHANÇA com uma ação de abordagem não é realmente fortuita !+) E a associação com a obra SIRESSES ou SORODAS provavelmente não é acidental: se, em resumo, qualquer processo artístico em ação nesta investigação-criação - ou necessariamente a comunicação resultante, o hipermédia em rede - é assim estabelecido antes de sua construção, através de um estudo dos fundamentos, um registo de traços ${ }^{20}$, então este aparato pedagógico e conceitual apoia-se, realiza-se nos territórios do seu uso. As Ciências da Informação e Comunicação (CIC) estruturam e questionam assim, como as Ciências da Arte, a conceção, a imaginação, a representação formal e a teorização

\footnotetext{
${ }_{19}$ A célebre voie lactée de Marcel Duchamp, Le Grand Verre ou La Mariée mise à nu par ses célibataires, même, 1915-1923, 19911992, 277,5 x 175,9 cm, réplica realizada por Ulf Linde, Henrik Samuelsson, John Stenborg, sob a supervisão de Alexina Duchamp, Óleo, folha de chumbo, fio de chumbo, poeira e verniz em chapa de vidro, folha de alumínio, madeira, aço, 321 x 204,3 X 111,7 cm, Moderna Museet, Stockholm.

20 "Para o investigador, o perigo é assimilar este traço ao próprio fenómeno - o que René Magritte explicitou no seu quadro Ceci n'est pas une pipe. Assimilar esse traço ao fenómeno pode levar a considerar o registro como uma prova irrefutável da existência do fenómeno. No entanto, se um tal traço não constitui uma prova, permite múltiplos usos pertinentes em contexto científico" (Lamboux-Durand, 2017, p. 29).
} 
desses dispositivos complexos. Às vezes cruzando alguns oceanos enevoados de certas certezas, e partindo - não sem um certo prazer - ao ataque de fronteiras consideradas inabaláveis, estes dispositivos parecem enfraquecer, de tempos em tempos, armadas inteiras de territórios estabelecidos, fortalezas julgadas invencíveis. Então, essas máquinas celibatárias ${ }^{21}$, ainda exacerbadas pelo digital e que são, antes de tudo, processos críticos abertos, logicamente alcançam o seu objetivo...

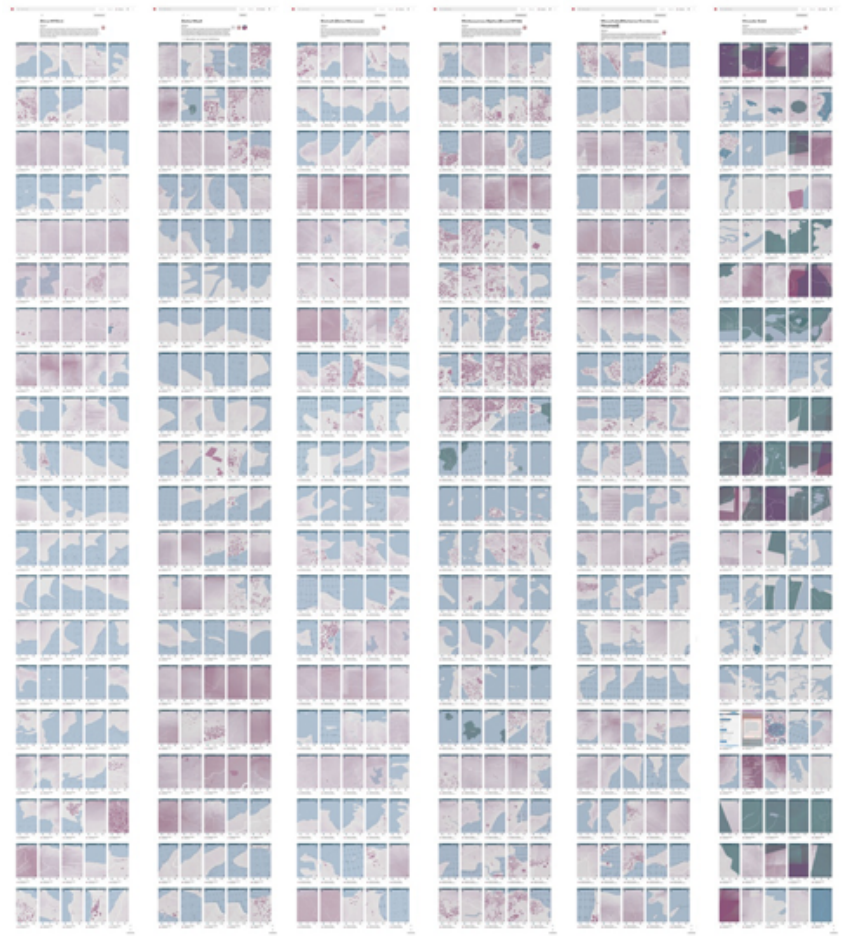

Figure 3: Brandon. Carole. 3 tiras, impressões digitais em papel, $90 \times 300 \mathrm{~cm}$, 2018. Esta imagem foi criada para a obra de arte hipermédia SORODAS

Fonte: https://www.pinterest.fr/siresse/boards/

\section{MAYOTte: ANTHRo/SOCIO ${ }^{22}$}

Neste workshop-laboratório, quatro professores-investigadores e artistas estão envolvidos: Carole Brandon (arte), Edwige Lelièvre/SIC, Ghislaine Chabert/SIC, Marc Veyrat/Art. A obra final é inicialmente planeada em torno de um dispositivo hipermédia pensado durante uma semana de workshop na Cité des Arts, em Chambéry, com os

\footnotetext{
${ }^{21}$ Pequenas piscadelas à noção de máquina celibatária i+M/PULSIONADA por Francis Picabia e Marcel Duchamp.

${ }^{22}$ Pequenas piscadelas a Bruce Nauman, Anthro/Socio (1991), instalação vidéo. "Anthro/Socio (Rinde Facing Camera) mostra em projeção gigante e em monitores o rosto de um homem que grita continuamente uma cantilena violenta: "Feed me, eat me, anthropology", "Help me, hurt me, sociology" e "Feed me, felp me, eat me, hurt me", disponível em https://www. letemps.ch/culture/bruce-nauman-libere-corps-cadre
} 
estudantes. Este dispositivo, ao aplicar-se num mapa - em três faixas de $90 \times 300 \mathrm{~cm}-$ expressaria remotamente por uma semana uma soma de dados - uma nova palavra colhida no local - vivida pelos alunos em Mayotte e pelas pessoas entrevistadas, $®$-JOGANDO provavelmente (-! pelo menos supomos isso !-) a lacuna cultural, as fragilidades identitárias, enquanto renova uma história comum de desigualdades, de in/visibilização... ${ }^{23}$

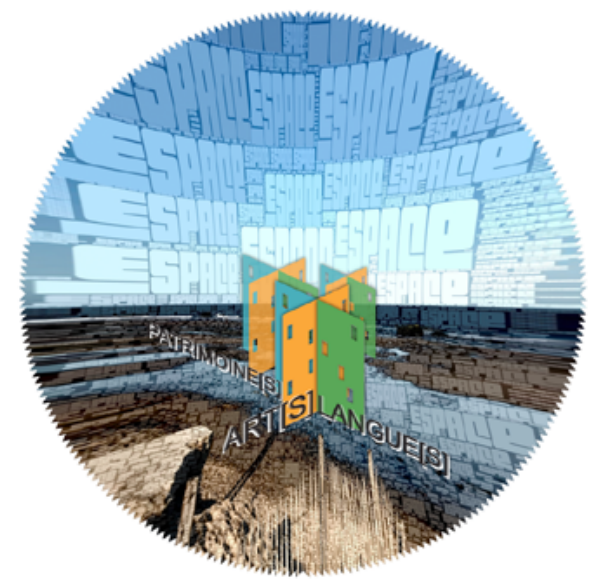

Figura 4: Este i+D/sign (-! information + Design / Sign !-) é o terceiro signo marcador da obra de arte hipermédia SORODAS

Créditos: Marc Veyrat, Société i Matériel, CréaTIC- IDÉFI Art[S] Langue[S] \& Patrimoine[S] Chambéry, i+D/signe, 2018

Mas, para isso, os estudantes também precisam descobrir Mayotte à distância... As notícias de atualidades, que chegam a partir dessa paisagem distante e fantasiada relatam através das redes sociais rumores de barreiras nas estradas, até tumultos e greves. A ira dos mahorais, os habitantes de Mayotte, encontra-se aparentemente ligada a questões de imigração clandestina (-! Mahorais.es / NÃO mahorais.es? Ou seja, a oposição entre os habitantes de Mayotte e os não-habitantes -), insegurança, falta de infraestruturas e um sentimento de abandono pela metrópole... As informações que circulam são contraditórias. Além disso, o envio ao local de reforços de polícia, como a chegada "de paraquedas" da ministra do Ultramar Annick Girardin, que se encontra com os atores locais, no dia 12 de março, na ilha Mayotte Primeira, sem que haja som no écran ${ }^{24}$, mesmo

\footnotetext{
${ }_{23}$ "Help me, hurt me": a questão do corpo ÉTRANGE-® [estranho/estrangeiro] encontra-se de fato no centro da obra SORODAS. Porque o processo de in/visibilidade mantido pelos média coloca os corpos i-MIGRANTES no limiar de uma política visível. "No centro da viagem presidencial a Mayotte, a questão da imigração. Quase um habitante em dois é de nacionalidade estrangeira. Em Mamoudzou, a capital administrativa do departamento ultramarino francês de Mayotte, essa taxa aproxima-se de $60 \%$. Uma situação que pesa bastante na situação demográfica, económica e social do departamento. O desequilíbrio aumentou ainda mais entre 2012 e 2017. O défice migratório dos nativos de Mayotte quase duplicou em relação ao período de 2007 a 2012, devido à saída, principalmente dos jovens, para a ilha La Réunion ou para a metrópole, por causa de escolas, universidades ou instalações de saúde inadequadas. No mesmo período, a migração líquida de nativos que vivem no exterior aumentou dez vezes. Alguns chegam a evocar o medo de 'uma grande substituição' da população. Nas eleições europeias de maio, o partido Rassemblement national (RN), dirigido por Marine Le Pen, conquistou 46,1\% dos votos em Mayotte". (Roger, 2019)

24 Disponível em https://www.facebook.com/mayottela1ere/videos/1700037426701954/. Os comentários são particularmente significativos sobre o estado de sítio que prevalece naquele momento.
} 
após o cancelamento de nossa viagem planeada de 11 a 19 de março, nada vai resolver. $O$ $i+D$ dessa fragilidade constante, de um destino fora das normas provocado pelas chatouilleuses ("cocequentas", em Português), associado aqui com SORODAS numa história da resistência, mulheres piratas e um mapa geolocalizado onde uma pessoa se perde (-! Com o aplicativo Brickx! -) é particularmente emocionante. Além disso, em Chambéry, seguimos os passos, as histórias i-REAIS ou não de viagens míticas, até os medos como as ilusões ou as dificuldades de uma imigração. E é aí que nossas aventuras antropológicas vão começar... Os métodos de discurso imaginados em seu redor como todos os problemas e questões relacionados a esses documentos coletados por estudantes que rapidamente interferirão na política...

Os alunos do Mestrado em Criação Digital são divididos em quatro grupos de pesquisa. KARIBOU ("Bem vindo" em mahorais), WAMI, EPISODIUS e S3K DANCE. Para encorajar o trabalho em antropologia visual, as instruções dadas por Ghislaine Chabert são simples: 1) pensar as ligações, a comunicação, as trocas entre os dois territórios; 2) trazer à tona questões culturais, espaços e temporalidades, linguagens; 3) a fim de permitir fazer algo anteriormente impossível, no dispositivo que será proposto em seguida na investigação-criação. Os quatro grupos precisam decidir sobre uma linha de investigação antes de começar a filmar as entrevistas. Esse eixo encontra-se naturalmente articulado em torno de noções que questionam as suas próprias práticas, os seus interesses recíprocos, imaginando o contexto de cada captura, determinante para a recolha de informações.

\section{HELL-O KARIBOU}

O KARIBOU estará interessado em histórias de vida relacionadas com fluxos migratórios $^{25}$. Para realizar o nosso estudo antropológico, optámos por realizar entrevistas filmadas. De fato, pelo nosso desejo de conhecer pessoas, de permitir que elas contem o seu território e as suas relações entre o departamento nativo e o local onde vivem hoje, esse formato impôs-se como uma evidência. Conhecer esses mahorais que moram em Chambéry [no sul de França] permitiu-nos interagir com eles: seja num café ou num ambiente mais privado, eles sempre tiveram prazer em trocar connosco essa cultura que é

\footnotetext{
25 "Dando um passo à frente, dois para trás, as leis apenas reverterão os privilégios concedidos aos migrantes. Assim, hoje em dia, na metrópole, a questão da identidade parece tão sensível para a segunda e terceira geração (e filhos e descendentes de imigrantes), bloqueados por uma névoa espessa, um tapete de incerteza e de ocultação das suas origens estrangeiras. Nem aqui nem ali, presos num lugar intermédio. Nesta tempestade societal, um jovem da França é inundado com o mesmo problema de pressão migratória tão (se não mais) importante do que na França metropolitana. Mayotte é um departamento francês do qual $40 \%$ da população é estrangeira. 'Le kwassa-kwassa pêche peu, il amène du Comorien, c'est différent': com esta frase desajeitada, o presidente Emmanuel Macron aponta o dedo a Mayotte, $0101^{\circ}$ departamento francês desde maio de 2011, submerso pela imigração ilegal" (Georges, Gervais, Carmona, Tagliafferi \& Vassileva, documento relacionado com o estudo de campo e não publicado, 2018). (-! A designação kwassa-kwassa (ou kwasa kwasa) é o nome usado nas ilhas Comores para barcos de pesca rápida, de sete a 10 metros de comprimento, um metro de largura, fundo chato e agora equipados com um ou dois motores. Fala-se igualmente do drama kwassa, para referir as pessoas que morrem todos os dias, ao tentar chegar a Mayotte, cuja travessia de $70 \mathrm{~km}$ num braço de mar conhecido por ser particularmente perigoso, entre Anjouan e Mayotte (“'Kwassa-kwassa': les Comoriens exigent des excuses de Macron, qui prône “'apaisement'”, 2017). Com esta frase, Macron queria significar que estas embarcações rápidas permitem uma emigração, ainda mais intensa e arriscada, para Mayotte.
} 
tão importante para eles. A entrevista filmada constitui um facto de palavra apoiado por imagens. Estas últimas dão-nos informações que o som por si só não teria transmitido. Além disso, isto contribuiu para descobrir Mayotte através de contos reais, histórias pessoais contadas e compartilhadas.

Assim, usámos um método qualitativo para coletar os dados. Essas entrevistas individuais ou de casais permitiram-nos construir histórias, cenários sobre o território de Mayotte. Assim, o nosso estudo baseia-se nos mesmos fundamentos de Durkheim (citado em Pharo, 2000): uma exploração da experiência que reúne os discursos dos atores e que traz à luz pensamentos, comportamentos sociais e estados mentais. Estas entrevistas muito pessoais, às vezes quase íntimas, permitiram-nos descobrir, para além das palavras, esses jovens mahorais. Segundo aquele autor, todos os elementos da sociedade, incluindo moralidade e religião, são produtos da história, que fazem parte do mundo natural e podem ser estudados cientificamente. Ele propõe um estudo da própria sociedade, antes de estudar as suas instituições.

Por isso, fizemos entrevistas semi-diretivas: tínhamos temas que queríamos discutir, mas a ordem variava de acordo com as conversas. Depois de colocar uma pergunta ou um novo tema, deixámos que o entrevistado se expressasse para ter um discurso mais verdadeiro e autêntico: uma história de vida, histórias contadas. Assim, apesar dos nossos interesses pessoais (cultura e imigração), privilegiámos experiências de vida e discursos espontâneos. Este método é uma maneira de se confrontar à alteridade do outro. O entrevistado é diferente e pode trazer-nos uma nova visão sobre as temáticas da pesquisa. Porque, de fato, se este modo de entrevista exige o estabelecimento de um terreno preciso, é preciso também aceitar os imprevistos, os acasos do diálogo.

Tivemos a oportunidade de entrevistar apenas homens Mahoran, as mulheres são mais tímidas quanto à ideia de se revelarem a estranhos e às suas câmaras. Embora muito desapontados por não termos obtido uma visão feminina, essa recusa geral testemunha uma forte vontade de permanecer discreto, de não ser exibido.

Do ponto de vista artístico, que mais nos interessa, observamos aqui os processos determinantes de uma futura implementação dos dispositivos de investigação-criação. Um relatório fictício é construído pela distância operatória imediatamente estabelecida no momento da recolha antropológica, através da encenação do diálogo gravado (-! Em sons e imagens !-) "A fábrica das histórias" ${ }^{26}$, embora seja produzida a partir de entrevistas sinceras, filmadas em lugares que provocam o tomar da palavra, causa o que Umberto Eco nomeia, baseando-se numa @LEITURA de Kant, uma synthèse spécieuse, ou síntese eventualmente ilusória devido à sua aparência de verdade:

como posso também entender, ao ver uma maçã vermelha ou uma pedra branca, que a maçã é branca por dentro e suculenta, ou que a pedra é dura no seu interior e pesada? Digamos que a diferença reside no fato de que o objeto percebido é o efeito de uma segmentação precedente do continuum

\footnotetext{
${ }^{26}$ La Fabrique des Histoires (-! responsável: Marc Veyrat !-) é um dos sub-eixos do eixo dois du Laboratoire LLSETI : Texte Image \& Arts Numériques, dirigido par Chislaine Chabert e Carole Brandon. Alba Marìn e Jacques Ibanez-Bueno participam nele igualmente.
} 
ou um objeto desconhecido. Quando vemos uma pedra, sabemos, no próprio ato de compreender que se trata de uma pedra, como é feita por dentro. Quem vê um esqueleto de coral pela primeira vez (algo que tem a forma de uma pedra, mas de cor vermelha) ainda não sabe como é feito lá dentro. (Eco, 1997, p. 111$)^{27}$

No caso dos alunos de KARIBOU, um imaginário é posto em prática, uma synthesis speciosa partir de atitudes, corpos presentes, palavras dadas, hesitações, silêncios. A imaginação é produtiva. É o mesmo processo em ação na questão do hipermédia: estamos continuamente diante de novos esqueletos de corais ... que sempre descobrimos pela primeira vez. Assim, produziremos significado extrapolando uma ficção sobre uma síntese de elementos sempre extraídos daquilo que chamamos de i-REAL ${ }^{28}$, ou seja, um conjunto realizado de informações que se tornam materiais artísticos. É uma espécie de ficção de facto[S], construída a partir de eSPAÇOs ${ }^{29}$ interconectados ao território sob observação, mas com duração limitada. Ora, longe de minimizar essa distância produtiva para nós entre a coleta dessas informações e o contexto da experiência ${ }^{30}$, e como toda a realidade é simplesmente $\mathrm{i}+\mathrm{M} / \mathrm{POSSÍVEL}$, como o que aconteceu com La Princesse QT son $M A C$, vamos experimentar, amplificar este contexto no ato da criação.

O nosso processo criativo é construído em duas etapas: primeiro, acumulamos fragmentos retirados da vida quotidiana, que organizamos em relações de laminação e encaixamento. Para isso, criamos sistemas autónomos em circuito fechado ou em loop que se desdobram em torno de uma figura central (-! objeto, pessoa, personagem, animal, forma, cores! -): esta colecta age como uma marca de referência ou um nó. A acumulação dentro do dispositivo (-! a montante ou não! -) cria uma forma aleatória de diário íntimo. A obra é um instante $t$ do dispositivo que depois dispersaremos sob outras formas. Carole Brandon ${ }^{31}$

\footnotetext{
${ }^{27}$ Umberto Eco acrescenta na página 115: "no prefácio da segunda edição da primeira Crítica, Kant evoca Tales que, partindo da figura de um triângulo isósceles para descobrir as propriedades de qualquer triângulo isósceles, entende que ele não deve seguir passo a passo o que ele vê na figura, mas deve realizar ou construir o triângulo isósceles em geral" (Eco, 1997, p. 115).

${ }^{28} \mathrm{O}$ I-REAL é apenas um estado transitório da informação em circulação, interagindo constantemente entre vários média.

${ }^{29} \mathrm{~A}$ obra em rede é sempre confrontada com uma distorção espacial e temporal. Entre o espaço-tempo físico dos utilizadores e o espaço-tempo do programa e das redes, este novo território emergente é um lugar híbrido - o eSPACE - constituído de ora em diante de espaços virtuais E i-reais, associados a temporalidades sobrepostas (Veyrat, 2015).

30 "Influência do contexto sobre a gravação: nas ciências experimentais, o contexto da experiência influencia a experiência em si, um dos objetivos dos investigadores é então identificar e minimizar, se possível, essas incidências. A compreensão e a tomada em conta do contexto da pesquisa, o dispositivo sociotécnico e as influências potencialmente produzidas, tornam assim possível não negligenciar os vieses. Durante uma gravação de depoimento, a presença do dispositivo sociotécnico de registo, as atitudes da equipe de gravação, a condução da entrevista, influenciam o depoimento e a sua receção durante a difusão (Lamboux-Durand, 2014). Além disso, todos os elementos não graváveis, os elementos afilmicos, devem ser levados em consideração" (Lamboux-Durand, 2017, pp. 37-38).
}

${ }^{31}$ Disponível em http://idefi-creatic.net/fr/publications/catalogues/ 


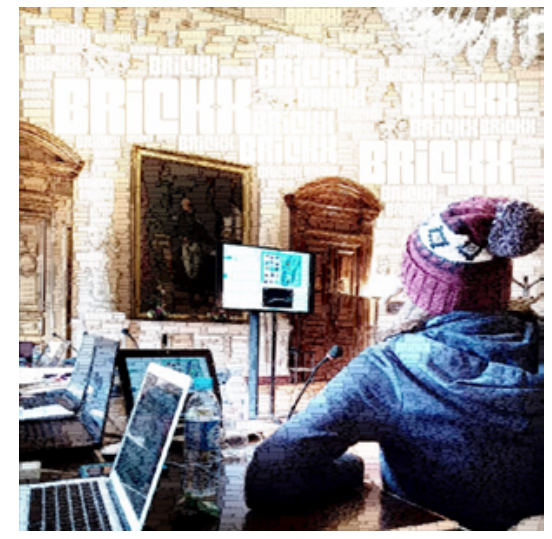

Figura 5: Apresentação do projeto Master 2 2iD, workshop SORODAS, Hôtel de Ville, Salle des Délibérations, Chambéry, 2018

Créditos: Marc Veyrat, Société i Matériel

\section{CONCLUSÃo E I-REVERÊNCIA}

Os fragmentos retirados das entrevistas vão misturar-se, fundir-se, i-MIGRAR para outras formas nos dispositivos de investigação-criação como estas colagens. E é aí que reside a distância elástica e não a oposição, entre Ciências da Informação, Comunicação e as Artes e as Ciências da Arte. O processo artístico i+M/PÕE, sem complexos mas também sem credulidade, uma distância do fato factual, uma transposição ficcional sem

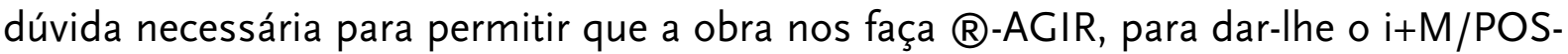
SíVEL de um lugar autónomo da arte, e ainda para nos instalar aí, ®CRIANDO o seu próprio território político.

No entanto, apesar dessa inevitável distanciação através dessa propulsão artística para além do i-REAL, o estudo antropológico - que desempenha um papel fundamental na instalação de dispositivos - permitirá rapidamente a emergência de outros problemas. Em Mayotte, uma residência artística foi estabelecida anteriormente em torno do documentário Sisygambis. Em relação aos vínculos entre o atelier-laboratório Art[S] Langue[S] e Patrimoine[S] através do Centro Universitário que supostamente receberia a equipa, o DAC (Direção dos Assuntos Culturais) que apoia o projeto Sisygambis ${ }^{32}$, os atores políticos locais: esses estudos antropológicos realizados em Chambéry pelos estudantes contudo em total liberdade, vão instalar-se num clima de desconfiança e tensão, ainda exacerbados no local pelos bloqueios de estradas e pelos vários incidentes que aumentarão gradualmente, até ao momento em que a nossa possível saída... já não será possível.

Os filmes serão alterados, várias informações terão que ser removidas das redes sociais...

Com o hipermédia, a i+D testada e comprovada de uma paisagem-programa, pro-

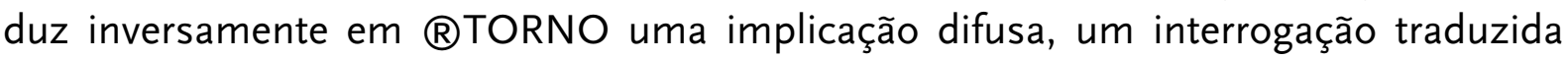

\footnotetext{
${ }^{32}$ Disponível em http://www.7portes.net
} 
aqui por uma propedêutica do eSPAÇO. Onde o espectador só pode tomar consciência, através das suas próprias experiências fenomenológicas, da distância que o aproxima ou o opõe às formas elásticas em constantes mutações de informação @PERCEBIDAS. Jorge Luis Borges escreve em La loterie à Babylone:

em muitos casos, a convicção de que certas alegrias eram obra do acaso teria diminuído a sua virtude; para combater este inconveniente, os agentes da Companhia usaram sugestão e magia. Os seus passos, as suas manobras permaneciam secretas. Para conhecer as esperanças íntimas e os terrores íntimos de cada um, eles dispunham de astrólogos e espiões. (Borges, 1983, p. 65)

Não faz sentido demonizar a nossa relação com o fluxo das redes sociais, com a internet, porque a informação não seria, por si só, certa ou errada. Mas transmitiria, através dos efeitos das suas manipulações e dos seus usos, um poder potencial desproporcional às esperanças ou terrores íntimos de cada um de nós; o seu perigo é simplesmente existir sob diferentes aparências e através de múltiplas conexões. A combinação constante, da equipa no Departamento de Comunicação Hipermédia, entre métodos visuais de investigação em Ciências da Informação e Comunicação, a fim de servir como base fenomenológica para os dispositivos da investigação-criação produzidos nas Ciências da Arte - como vimos - causa misturas explosivas. Será necessária alguma moderação: o i-REAL é uma caixa de Pandora.

Tradução: Pedro Andrade

\section{REFERÊNCIAS}

Borges, J. L. (1983). La loterie à Babylone. In Fictions (pp. 61-70). Paris: Éditions Gallimard.

Brandon, C. (2016). L'Entre [corps/machine]: la princesse et son Mac. Tese de doutoramento, Université Paris 1 Panthéon-Sorbonne, Paris, França. Retirado de https://hal.archives-ouvertes.fr/tel-02111485

Brandon, C. (2002). Mille Sabords ou les origines de la vidéo dans la peinture. Dissertação de Mestrado, Université Jean Monnet, Saint-Étienne, França.

Eco U. (1997). Kant et l'ornithorynque. Paris: Éditions Grasset.

Foucault, M. (2001). Le jeu de Michel Foucault. In Dits et écrits II (pp. 62-93). Paris: Éditions Gallimard.

Foucault, M. (1979). Histoire de la sexualité, tome I. Paris: Éditions Gallimard, Paris.

Foucault, M. (1984a). Histoire de la sexualité, tome II. Paris: Éditions Gallimard, Paris.

Foucault, M. (1984b). Histoire de la sexualité, tome III. Paris: Éditions Gallimard, Paris.

Foucault, M. (1993). Surveiller et punir. Paris: Éditions Gallimard.

"Kwassa-kwassa": les Comoriens exigent des excuses de Macron, qui prône "l'apaisement". (2017, 05 de junho). Le Monde. Retirado de https://www.lemonde.fr/afrique/article/2017/06/05/apres-les-proposchoquants-de-macron-les-comoriens-exigent-des-excuses_5139073-3212.html 
Lamboux-Durand, A. (2017). Appréhender les biais de l'audiovisuel pour une analyse scientifique appropriée des situations enregistrées. Cuadernos Artesanos de Comunicación, 136, 27-46. Retirado de http://www. cuadernosartesanos.org/2017/cac136.pdf

Parvard, B. (2010). Qui sont les 343 du manifeste d'avril 1971? In C. Bard (Ed.), Les féministes de la deuxième vague (pp. 71-84). Renes: PUR.

Pharo, P. (2000). Le sens objectif des faits sociaux. Revue européenne des sciences sociales, 38(119). https://doi. org/10.4000/ress.679

Roger, P. (2019, 21 de outubro). Mayotte : au cœur du voyage de Macron, la question de l'immigration. Le Monde. Retirado de https://www.lemonde.fr/politique/article/2019/10/21//-immigration-clandestine-auc-ur-de-la-visite-de-macron-a-mayotte_6016370_823448.html

Soudan, F. (2010). Penombra. Dissertação de Mestrado, Université Paris 1 - Panthéon-Sorbonne, Paris, França.

Veyrat, M. (2015). eSPACE. In G. Azémard (Ed.), 100 Notions pour l'Art Numérique(pp.86-88). Paris: Les Éditions de l'Immatériel. Retirado de http://www.10onotions.com

\section{NOTA BIOGRÁFICA}

Carole Brandon é artista, Professora Associado de Ciências da Arte e de Artes Plásticas. Membro do Laboratório de Línguas, Literaturas, Sociedades, Estudos Transfronteiriços e Internacionais, Departamento de Comunicação Hipermédia, Universidade Savoie Mont-Blanc. Responsável da Collection 28, Edições de Imprensa da Universidade Savoie Mont-Blanc. Responsável pelo Mestrado em Criação Digital (-! Inicial e alternância! -) e pelo mestrado 2iD em alternância (-! Interatividade e Design da Informação! -).

ORCID: https://orcid.org/oooo-0002-1487-3887

Email: carole.brandon@univ-smb.fr

Morada: UFR LLSH, Route du Sergent Revel, 73000 Jacob-Bellecombette, França

Marc Veyrat é artista, Professor de Ciências da Arte e Associado de Artes Plásticas. Investigador do Laboratório de Línguas, Literaturas, Sociedades, Estudos Transfronteiriços e Internacionais, Departamento de Comunicação Hipermédia, Universidade Savoie Mont-Blanc. Chefe da equipa "Les Fabriques des Histoires" e chefe da Text Q Image Collection, Edições Edições de Imprensa da Universidade Savoie Mont-Blanc. Investigador associado da UNESCO Chair / ITEN (-! Inovação, transmissão e publicação digital! -). Diretor do Departamento de Comunicação Hipermídia, Universidade Savoie Mont-Blanc.

ORCID: https://orcid.org/oooo-0003-0711-8557

Email: imateriel@gmail.com

Morada: UFR LLSH, Route du Sergent Revel, 73000 Jacob-Bellecombette, França

\section{Submissão: 10/09/2020 \\ Aceitação: 29/11/2019}

